\title{
Gênero, geração e trabalho: modos de vida de idosos/as residentes em zona rural
}

\author{
Suzana Almeida Araújo*, Baruc Correia Fontes** \\ Mônica Dayse de Souza Carvalho"**, Joselaine Marília Melo Fontes Nascimento "***
}

\section{Resumo}

Este artigo traz informações obtidas por meio de pesquisa realizada no âmbito do Núcleo Integrado de Pesquisa em Psicologia Social e Saúde da Faculdade Ages, Paripiranga - BA. A proposta referiu-se à investigação dos processos psíquicos do envelhecimento atrelados à realidade do trabalho rural, sob o recorte analítico dos estudos de gênero, buscando-se analisar o significado da velhice e da experiência de envelhecer relacionados ao bem-estar psicossocial, os sentidos que cada idoso atribui ao seu papel ocupacional e à vivência da aposentadoria, investigar de que modo as construções sociais de gênero perpassam esses sentidos, bem como as experiências de trabalho na terceira idade, atreladas à organização familiar e outras situações sociais. As atividades foram desenvolvidas na cidade de Paripiranga - BA e foram divididas em três eixos: gênero, geração e trabalho, sendo que aqui o foco recai sobre o recorte analítico de gênero. Foram realizadas 11 entrevistas com idosos, sendo seis homens e cinco mulheres, dos quais oito são moradores/as do campo e três da área urbana, mas apresentam algum vínculo com a zona rural. Para o levantamento de informações, utilizou-se um roteiro semiestruturado contendo: 12 questões de identificação pessoal; 17 questões sobre qualidade de vida e processo de envelhecimento; sete questões sobre trabalho e aposentadoria; sete questões sobre gênero e funções familiares. Os aspectos comumente atrelados ao bem-estar dos idosos estão na esfera ocupacional, relacional e de saúde. O trabalho é visto, tanto por idosos homens quanto por idosas mulheres como importante fator de satisfação, em virtude de evitar a ociosidade, bem como para garantir o sustento

* Psicóloga pela Universidade Federal de Santa Catarina e Mestre em Psicologia pela Universidade Federal de Santa Catarina, professora da Faculdade de Ciências Humanas e Sociais - AGES, Paripiranga/BA, coordenadora do Núcleo Integrado de Pesquisa em Psicologia Social e Saúde. Endereço para correspondência: Faculdade AGES, Avenida Universitária, 23. Parque das Palmeiras. CEP: 48430-000, Paripiranga - BA. E-mail: psisuzana@gmail.com.

** Acadêmico do curso de graduação em Psicologia da Faculdade de Ciências Humanas e Sociais - AGES, Paripiranga - BA.

*** Acadêmica do curso de graduação em Psicologia da Faculdade de Ciências Humanas e Sociais - AGES, Paripiranga - BA.

***** Acadêmica do curso de graduação em Psicologia da Faculdade de Ciências Humanas e Sociais - AGES, Paripiranga - BA.

$\rightarrow$ http://dx.doi.org/10.5335/rbceh.2013.2977 
da família. As mulheres, responsáveis especialmente pelos cuidados domésticos, continuam a exercê-lo e, por sua vez, trazem um envolvimento mais ativo em atividades fora do lar e em situações de convívio social.

Palavras-chave: Gênero. Trabalho. EnveIhecimento. Saúde. Zona rural.

\section{Introdução}

O presente artigo traz informações obtidas por meio de pesquisa realizada no âmbito do Núcleo Integrado de Pesquisa em Psicologia Social e Saúde da Faculdade Ages, Paripiranga - BA. A proposta referiu-se à investigação do processo de envelhecimento vinculado à realidade do trabalho rural, com a abordagem analítica dos estudos de gênero. As atividades foram desenvolvidas na cidade de Paripiranga e divididas em três eixos: gênero, geração e trabalho. Aqui é dado o enfoque sobre a construção social de gênero e como essa categoria atravessa o cotidiano dos idosos no que diz respeito às vivências do trabalho e do envelhecimento.

O processo de envelhecimento ganha contornos específicos conforme o tempo e o espaço em que se manifesta, ou seja, trata-se de um processo sócio-histórico, datado e localizado. Assim, o envelhecer ganha uma significância própria na atualidade, vivenciado de forma singular por sujeitos e grupos sociais. As representações sociais do envelhecimento delineiam modos de vida, modos de pensar e agir próprios de uma dada realidade, sendo valorados conforme o lugar social que ocupa o idoso.
Pode-se hoje observar uma mudança substancial na vivência da velhice, conforme atesta Silva, refletida em hábitos, imagens, crenças, bem como uma mudança no próprio conceito:

De fato, a modificação da sensibilidade investida sobre a velhice acabou gerando uma profunda inversão dos valores a ela atribuídos: antes entendida como decadência física e invalidez, momento de descanso e quietude no qual imperavam a solidão e o isolamento afetivo, passa a significar o momento do lazer, propício à realização pessoal que ficou incompleta na juventude, à criação de novos hábitos, hobbies e habilidades e ao cultivo de laços afetivos e amorosos alternativos à família (p. 161).

Sustenta-se um ideal de vida após os 60 anos, pautado no lazer, no cuidado de si (e não mais dos outros), em uma vida relativamente dinâmica, destituída das amarras laborais, dedicada apenas aos interesses próprios. Porém, esse período é também marcado por um processo de restrição de determinadas funções como autonomia, capacidade para tomar decisões, condições de saúde, gerando situações de isolamento social, solidão, dependência. No entanto, conforme sustenta Gusmão (2011), "o que está em jogo ao envelhecermos não é o envelhecer, mas o como envelhecemos. O como importa, principalmente pela capacidade de cada um em mudar e aceitar a mudança não só do corpo, mas de sua própria interioridade", incidindo diretamente nas expectativas de vida de cada um. Trata-se, assim, de um processo sentido na interioridade, porém permeado pelas representações que delimitam essas vivências particulares. 
O trabalho, por sua vez, apresenta-se como elemento estruturante da nossa organização social e marca de forma significativa a vida dos indivíduos. O grupo geracional em questão é marcado especialmente pela ausência de atividade laborativa, em decorrência da aposentadoria ou da falta de oportunidades no mercado, mas, uma parcela mantém-se, por opção ou necessidade, ainda em atividade, principalmente no setor informal. A maneira como o trabalho e a aposentadoria são percebidos está atrelada à história de vida dos sujeitos, "apresentando múltiplas interfaces, que estão relacionadas às mudanças na vida social e no mundo do trabalho (...), ao convívio dentro e fora do trabalho, à rotina laborativa, aos papéis sociais desempenhados, [...] aos projetos de vida" (BULLA; KAEFER, 2003, p. 2), entre outros.

Além da condição etária/geracional/ laboral, as categorias de gênero apresentam-se também como uma fonte de análise importante quando se trata de investigar modos de vida, na medida em que regem as relações estabelecidas entre os sujeitos, situando-os na rede social, a partir da atribuição e apropriação de papéis por parte dos indivíduos. Gênero é aqui entendido como a construção social sobre corpos sexuados, compreendendo os delineamentos sociais acerca do masculino e do feminino. Seus vetores de ação se expressam tanto na constituição dos sujeitos quanto na organização da sociedade, enquanto um modo de ordenamento/regulação das práticas sociais (SCOTT, 1990).
Motta (2011) observa que "há uma especificidade de gênero na velhice", pois a condição de idade afeta de maneira diferente homens e mulheres. Essa diferença se expressa nos comportamentos, na expectativa de vida, nas atividades cotidianas, na vivência sexual, etc. A autora aponta que, pelas mulheres, a velhice é vivida com satisfação e liberdade, sendo uma fase de muitas possibilidades, enquanto os homens a entendem como um momento de descanso, em virtude da aposentadoria. De todo modo, é um período tanto de mudanças, como de permanências, onde $o$ antigo e o novo misturam-se, num limiar de contradições e pluralidades.

O envelhecimento faz parte de um conjunto de processos que provocam uma série de modificações de ordem biológica, psicológica e social. É importante conhecermos esse processo e suas repercussões na vida dos sujeitos, tentando captar a postura adotada diante de tais transformações, considerando, ainda, possíveis limitações quanto às opções de lazer e acesso aos serviços que existem na zona rural, tomando-os como aspectos importantes para a promoção da qualidade de vida. Em suma, a escolha desse tema justifica-se pela ausência de estudos e pesquisas na zona rural, conforme identificado na pesquisa bibliográfica realizada ${ }^{1}$, enfatizando as relações entre gênero, trabalho e a experiência do envelhecimento nesse contexto.

A despeito dos muitos outros marcadores sociais que atravessam os modos de ser e práticas cotidianas, focaremos nossa investigação nestes três 
elementos - geração, trabalho e gênero -, tendo por objetivos: analisar o significado da velhice e da experiência de envelhecer relacionados ao bem-estar psicossocial; compreender os sentidos que cada idoso atribui ao seu papel ocupacional e à vivência da aposentadoria; investigar de que modo as construções sociais de gênero perpassam esses sentidos, bem como as experiências de trabalho na terceira idade, atreladas à organização familiar e outras situações sociais. Busca-se compreender como esses elementos apresentam-se no universo alvo da investigação, e, em última instância, dar subsídios para a formulação de estratégias de intervenção voltadas ao atendimento das demandas dessa população.

\section{Método}

A pesquisa caracteriza-se como qualitativa, realizada com moradores da cidade de Paripiranga - BA. A cidade está localizada aproximadamente a 340 $\mathrm{km}$ da capital baiana, com uma população aproximada de 28.340 habitantes, sendo a maioria residentes da zona rural (cerca de 66\%) e tem a agricultura como principal atividade econômica ${ }^{2}$.

A amostra foi composta por pessoas idosas com idade de 65 anos ou mais, identificadas por meio de visitas domiciliares. As localidades visitadas foram escolhidas mediante caracterização desses espaços como sendo de zona rural, situadas nas imediações da cidade. Com o auxílio dos moradores, foram identificadas residências compostas por idosos, que foram convidados a participar da pesquisa por meio da concessão de uma entrevista. À medida que os sujeitos foram sendo identificados, forneciam também indicações de outras pessoas que atendiam aos critérios. Foram realizadas 11 entrevistas, das quais seis com homens e cinco com mulheres, dos quais oito são moradores do campo e três vivem em área urbana, mas apresentam algum vínculo com a zona rural (passam alguns dias da semana ou lá viveram a maior parte de suas vidas). As três entrevistadas da zona urbana são participantes da Faculdade Integrada da Terceira Idade (FINATI), um projeto da Faculdade Ages que oferece disciplinas e outras atividades voltadas para essa população. Todos assinaram o Termo de Consentimento Livre e Esclarecido. A pesquisa foi avaliada e aprovada pelo Conselho de Ética da Faculdade Ages, em 30 de maio de 2012, sob o protocolo número 020/2012.

Para o levantamento de informações, utilizou-se um roteiro semiestruturado contendo: 12 questões de identificação pessoal; 17 questões sobre qualidade de vida e processo de envelhecimento; sete questões sobre trabalho e aposentadoria; sete questões sobre gênero e funções familiares. A maioria das entrevistas ocorreu na casa dos idoso e três foram realizadas nas dependências da faculdade. O áudio de todas as entrevistas foi gravado e, posteriormente, o material foi digitalizado. Tinham duração média de 20 a 40 minutos.

Procedeu-se à análise de conteúdo temático das informações, conforme proposto por Laurence Bardin (1979), que permite organizar os resultados 
por temas, conforme o objetivo analítico visado. As entrevistas foram transcritas e submetidas à leitura, quando as informações obtidas foram separadas em eixos temáticos, agrupando-se as falas dos entrevistados, que foram posteriormente analisadas com base na literatura especializada. Os resultados foram divididos em quatro grandes categorias e subdivisões, assim distribuídas: 1) dados de identificação e características sociodemográficas; 2) processo de envelhecimento, saúde e bem-estar psicossocial; 3) trabalho e aposentadoria; 4) cuidado da casa e dos filhos; todos atravessados pela categoria analítica de gênero. A seguir, são apresentados os resultados em conjunto, abrangendo esses quatro eixos.

\section{Resultados e discussão}

Na Tabela 1, apresentam-se os dados de identificação dos entrevistados, cujos nomes foram, aqui, alterados por nomes fictícios. Observa-se que todos os participantes homens têm seu trabalho voltado para a agricultura, assim como duas participantes mulheres. Apenas uma das mulheres, dentre as três, exercia atividade remunerada fora de casa, atuando como técnica em enfermagem. No momento da entrevista, três dos homens não trabalhavam mais e três desenvolviam atividades da lavoura. Todos recebem aposentadoria, o que lhes garante o sustento, e dois, Josué e Manoela, recebem, ainda, pensão por viuvez. Duas informaram morar sozinhas e os demais vivem na companhia do marido/esposa e/ou filhos. Todos seguem a religião católica.

Tabela 1. Dados de identificação dos sujeitos entrevistados

\begin{tabular}{|c|c|c|c|c|c|c|}
\hline Nome & Idade & Profissão & Estado civil & № filhos & Com quem mora & Trabalha? \\
\hline Jurandir & 73 & Agricultor & Casado & $\begin{array}{l}5 \text { vivos } \\
2 \text { mortos }\end{array}$ & 2 filhos e 1 neto & Ocasionalmente \\
\hline Jailson & 75 & Agricultor & Casado & 8 & Esposa & Não \\
\hline Juvenal & 81 & Agricultor & Casado & 13 & Esposa e 1 filha & Ocasionalmente \\
\hline Oswaldo & 86 & Agricultor & Casado & 7 & Esposa & Não \\
\hline Josué & 82 & Agricultor & Casado & 12 & Esposa, 1 filho & Não \\
\hline Jeová & 69 & Agricultor & Casado & 6 & Esposa & Na roça \\
\hline Mercedes & 76 & Agricultora/Do lar & Casada & 6 & Esposo & Doméstica \\
\hline Bianca & 65 & Do lar & Casada & 5 & Esposo & Doméstica \\
\hline Amanda & 73 & $\begin{array}{l}\text { Costureira/ } \\
\text { Agricultora }\end{array}$ & Solteira & Não & Sozinha & Costureira \\
\hline Manoela & 70 & $\begin{array}{l}\text { Técnica em } \\
\text { Enfermagem }\end{array}$ & Viúva & 4 & Sozinha & Não \\
\hline Marisa & 67 & Do lar & Casada & $\begin{array}{l}3 \text { vivos } 1 \\
\text { morto }\end{array}$ & Esposo & Doméstica \\
\hline
\end{tabular}


Dos entrevistados, somente sete continuavam a trabalhar (conforme se pode observar na Tabela 1). A importância do trabalho é atribuída especialmente ao fator ocupação e subsistência financeira para a manutenção da família. Amanda sempre exerceu a função de lavradora, o que garantiu seu sustento ao longo da vida. No momento, identifica-se como costureira, o que lhe confere alguma renda extra, mas costuma costurar principalmente para a família (sobrinhos, irmãos). Afirma que a vivência do trabalho traz algo prazeroso: "Melhora a cabecinha, se diverte, é como uma terapia". Para Manoela, outra entrevistada, ter uma ocupação é visto como algo promotor de saúde: "você não vai ter saúde sem trabalho, porque vai se preocupar, dá pra endoidar". Essa foi a única dentre as entrevistadas que indicou ter tido na sua experiência de trabalho um vínculo empregatício, as demais se mantiveram com as tarefas domésticas ou mesmo na agricultura familiar. Duas idosas apontam para a importância do cuidado da casa, já que ambas não trabalhavam fora.

Entre os homens, constata-se também a atribuição de sentidos ao trabalho como algo que lhes dá prazer, permite a subsistência da família e os mantêm ocupados. Três deles permanecem trabalhando na lavoura, ocasionalmente, para complementação da renda familiar. "Rapaz, a importância do trabalho pra minha vida é plantar e ver a safra, pra colher alguma coisa, pra ter com que passar e se arrimigar com o trabalho né, porque aposentadoria, se for pra viver de aposentadoria não dá, o salário não dá pra nada." (Jeová). O trabalho faz parte de suas rotinas desde muito cedo, apontam para a satisfação e o prazer que este lhes confere. "Me mantenho trabalhando porque gosto de trabalhar. Gosto de tá parado não, gosto de lutar com meu cabritos. Tenho um irmão que parou de lutar, mas, quero não" (Jeová); "Eu num fui homem de festa, não gostava de festa, nem disso, daquilo, agora o meu divertimento era minhas luta" (Josué). Jeová e Josué remetem o trabalho à condição de luta. Trata-se de uma luta travada diariamente para garantir a subsistência da família, dependente exclusivamente da lavoura, que demanda intenso esforço físico em algumas tarefas e conta com a participação de todos os familiares.

No que concerne à oferta local de trabalho para homens e mulheres, as opiniões foram divididas: todas as mulheres afirmaram que as oportunidades são iguais para ambos, já a maioria dos homens acredita que os homens têm mais possibilidades de emprego. Ainda assim, duas mulheres optaram por permanecer exclusivamente com o trabalho doméstico. "Aqui trabalha mais os homens, mulher não trabalha não. Trabalhar em quê? Os homens faz uma rocinha e as mulheres, fazer o quê? Toma conta da casa..." (Jailson). Com relação aos tipos de trabalhos que são fornecidos, os informantes indicam que para homens são os serviços de pedreiro e agricultura, e para as mulheres consideram a costura, bordado e faxina.

Abramo (2001) leciona que a imagem da mulher permanece associada ao seu lugar de reprodutora, a mulher-família e dona de casa, imagem que se sobrepõe à da mulher trabalhadora. As características dessa representação são 
colocadas como barreiras e limitações para a inserção da mulher no mercado de trabalho. Essa inserção é permeada por "imagens de gênero", entendidas como "configurações das identidades masculina e feminina, produzidas social e culturalmente" (p. 89), que determinam o lugar que homens e mulheres ocupam no mercado de trabalho, tanto no que se refere às oportunidades de acesso, quanto às condições em que este se desenvolve.

Bruschini (1998) traz também o aspecto familiar, apontando que a participação da mulher no mercado de trabalho está condicionada a fatores referentes não somente à sua qualificação e à oferta de emprego, como ocorre no caso dos homens. Está envolvida a construção de uma identidade em torno do ambiente doméstico, a necessidade de se articular papéis familiares e profissionais, e depende, ainda, da combinação de características pessoais e familiares, "como o estado conjugal e a presença de filhos, associados à idade e à escolaridade da trabalhadora" (p. 17), bem como o ciclo de vida e a estrutura familiar.

Buscou-se também averiguar os tipos de serviços que ambos exercem em suas casas. Quatro homens afirmaram nunca terem participado de nenhuma tarefa doméstica, nem mesmo de manutenção da casa; três mulheres alegaram serem as únicas responsáveis pelo serviço doméstico em seus lares. Jailson aponta: "a mulher que cuidava e eu trabalhava para dar o sustento. A função da mulher é tomar conta da casa e o homem trabalhar pra dar o sustento à família”. A justificativa está na atribuição do papel de cuidadora e mantenedora como sendo intrinsecamente feminino, não fazendo sentido, portanto, a participação do homem. "Ele [o esposo] toma conta da roça e criação, e eu cuido de tudo da casa." (Marisa). "As mulheres cozinham, lavam, esses negócios, e o homem nada, não faz nada porque não tem nada pra fazer". (Juvenal).

A participação do homem na esfera doméstica é fenômeno recente e passa a ser tema de estudo na década de 1980, conforme aponta Lyra da Fonseca (1998). Enquanto a mulher ganhava espaço no mercado de trabalho, assumia uma dupla jornada, mantendo-se a única responsável pelas tarefas domésticas. A não participação masculina passa a ser problematizada, buscando-se compreender as condições criadas na sociedade que facilitam ou dificultam o envolvimento do homem na vida familiar. Hoje, é possível falar em novos arranjos familiares, nos quais foram redefinidas as relações de gênero e as atribuições paternas e maternas. Ainda assim, a mulher continua sendo considerada a principal cuidadora dos filhos, e a participação masculina, uma "ajuda" (RIDENTI, 1998). O reconhecimento da paternidade se dá na dimensão econômica, como provedor.

Juvenal afirma que educar não é somente dever da mãe , mas "o papel da mãe e da família é ensinar a filha a trabalhar, fazer as tarefas da casa, nas atividades domésticas, para quando crescer poder fazer as coisas, porque se criam sem saber fazer as coisas né, não dá certo". Ressalta-se o papel da mulher na perpetuação das representações e atribuições de gênero, na medida em que se situa como educadora e responsável por salvaguardar a transmissão dos valores que compõem a família. 
Entre os seis homens entrevistados, quatro consideram-se o chefe da casa, alegando que proveem a esposa, "porque eu sou o dono da casa e quem manda" (Jailson). Afirmam, ainda, que no meio em que vivem quem tem que ser o chefe é o homem. Juvenal diz que é a esposa "quem dita as regras na casa, como diz a prosa, é a mulher, o homem manda na roça". Um homem entre os analisados afirma que sua mulher é quem comanda a casa, pois ele está doente e "ela é quem faz tudo dentro de casa". Marisa traz a seguinte colocação: "ele não morreu ainda, depois que morre é que é a mulher". $\mathrm{O}$ lugar de comando se estabelece ainda como território masculino, sendo possível ser assumido pela mulher apenas diante da ausência do esposo. Por sua vez, é na esfera privada que a mulher ocupa um lugar de poder, na medida em que é reconhecida como "dona do lar", ainda que não seja considerada a figura central de autoridade.

Os sujeitos são representantes dos modelos tradicionalmente estabelecidos para homens e mulheres e o reproduzem em seu cotidiano, buscando transmiti-los às novas gerações. As respostas indicam que esses indivíduos sentem-se confortáveis (ou conformados) em tais papeis, mesmo reconhecendo que ocorreram mudanças nas relações sociais o que é percebido, por eles, como prejudicial, principalmente no que diz respeito à liberdade conquistada pela mulher, à falta de controle sobre os membros da família e à diminuição do exercício de comando dos homens. De modo geral, mantém-se a divisão social do trabalho, pois ao homem atribui-se a função de prover e à mulher a de cuidados domésticos, ainda que, entre essas funções, haja práticas voltadas ao sustento da família.

Na velhice, há uma manutenção de tal função por parte das mulheres, que a desempenham até que as limitações físicas as impeçam, sendo, inclusive, responsáveis por cuidar do marido idoso. No caso dos homens, a agricultura possibilita a permanência no exercício do trabalho, já que trabalham para si mesmos e o executam na medida do possível. As funções das mulheres exercidas na velhice apresentam-se como continuidade de um papel sempre desempenhado, enquanto, para os homens, a velhice coloca-se como ruptura de um lugar antes estabelecido e que agora não mais pode ocupar.

Um deles menciona a sobrecarga de trabalho que recai sobre a mulher em virtude da sua condição de saúde: "eu acho no meu pensamento, quem não tem saúde, só dá trabalho a mulher. Se a mulher for forte ainda dá um passo, se a mulher for fraca, aí desmantela tudo. Aí têm que trazer os vizinhos, os parentes, as tias, pra cuidar da pessoa." (Jurandir). $\mathrm{O}$ ato de cuidar perpassa a trajetória da mulher como atividade fundamental, e assim persiste, a despeito das próprias limitações, visto que em nenhuma das falas apareceu a necessidade ou o desejo de ser cuidada. Trata-se de um elemento constituinte da subjetividade feminina, "essas mulheres foram educadas e preparadas, salvo algumas exceções, para a dedicação completa ao outro. Essa devoção é vista como essencial para a manutenção e preservação dos integrantes de sua família, bem como de seus princípios e valores" (DUARTE; SANTOS, 2004). 
Contudo, ante a ausência dos filhos, o que poderia ser percebido como uma lacuna na vida dessas mulheres pode também ser vivenciado como um momento de ressignificações e de um voltar para si.

Indagadas acerca de suas vivências no processo de envelhecimento, cinco das mulheres entrevistadas consideram esse processo como algo bom, remetendo a um olhar positivo sobre a velhice, como diz Bianca: "porque quando a gente envelhece, não morre novo, já viu muitas coisas com 65 anos, já viu bastante coisa", apontando para a longevidade como um critério favorável. Amanda indica estar conformada com a inevitabilidade do envelhecimento, ressaltando o ganho em termos de "mais experiência de vida" que ele proporciona: "Oh, chega a idade e pronto, né? Que que a gente pode fazer, né? Tenho prazer disto". Duas das mulheres que são participantes da FINATI apontam para a liberdade adquirida nessa fase, ou seja, a possibilidade de ser livre, podendo fazer o que quiser sem preocupações, em virtude de não mais trabalharem. "A aposentadoria foi uma paz na minha vida" (Marisa). As idosas que têm uma vida mais restrita ao campo enfatizam o fato de terem saúde (ou a ausência de doenças) como valorização positiva.

Entre os depoimentos, não aparece de forma prevalente uma conotação negativa atribuída à velhice, como comumente se observa em depoimentos de idosos (FERNANDES; GARCIA, 2010). A ênfase aqui recai na longevidade e numa velhice vivida em condições de saúde consideradas satisfatórias. Por sua vez, quanto às expectativas para $o$ futuro, temem a perda de autonomia e as condições incapacitantes que podem vir a enfrentar. "A velhice é muito ingrata, a gente devia terminar nossos dias assim, por exemplo, como estou, ficasse desse jeito, não ficasse mais velha. Mas, depois você fica andando como neném, se arrastando, fica a mesma coisa, dependente" (Manoela). Por vezes, sequer vislumbram o futuro, como demonstra Mercedes: "Num tenho futuro, que futuro tem uma pessoa que é de idade?". A ele está atrelada a presença iminente da morte, comum nesse momento da vida, como indica Ribeiro, "o envelhecimento traz consigo a perspectiva da morte. Mesmo com o aumento da sobrevida da população humana, a vida é sempre um período finito. Esta finitude passa a ser mais contundente com a chegada da velhice. A perda de amigos, de familiares e de pessoas de referência social reforça essa característica" (2008, p. 55).

Da parte dos homens, quanto ao envelhecer, sentem as consequências do trabalho braçal como algo agravante para sua saúde e, consequentemente, sua qualidade de vida. Eles prezam pela estabilidade financeira adquirida com a aposentadoria, da qual provém o sustento da casa; apreciam também a possibilidade de ter uma vida mais flexível, que não seja exclusivamente voltada para um trabalho do qual a sua família dependa para sua sobrevivência. Trazem ainda a oportunidade de ter vivido tanto tempo: "A vida da gente é essa. Muitos [dizem] 'ai, ai que eu chegasse a sua idade'. Eu tô bem conformado que já tô com essa idade toda e criei a minha família e rodei o mundo" (Josué); "Envelhecer é bom, porque, a pessoa se não envelhecer, tem que morrer novo, né? (risos)" (Juvenal). Entre os entrevistados, fica latente a necessidade de uma ocupação. Para os homens, 
é difícil aceitar essa nova realidade em que não está incluso o trabalho, isso os desestimula e não cria perspectivas no porvir, como fala Jeová: "Enquanto eu puder fazer minhas coisinhas eu faço, todo dia faço uma coisinha na roça, na cidade", evidenciando a necessidade de manter-se em atividade. Todos parecem almejar pela continuidade de sua vida laboral, mas deparam-se com as limitações físicas e começam a nutrir um sentimento de aceitação, como fala Josué: "de agora pra frente é como se diz, ter o dinheirinho da minha feira, os remedinho, até o dia que Deus me chamar".

Em estudo similar, Fernandes e Garcia (2010) encontram sentidos como finitude, doença, problemas e limitações atribuídos à velhice. Nesse sentido, essa fase da vida permanece, no imaginário social, vinculada à degradação biológica, sentida pelos sujeitos aqui investigados, como impossibilidade para experiências plenas. Por sua vez, não se detectam dificuldades de aceitação da velhice propriamente dita, visto que muitos a veem como um processo inevitável e demonstram mesmo uma postura de conformação diante dela. Isso pode estar atrelado a poucas expectativas quanto ao futuro, conforme observado em algumas falas, compreendendo-se que atingir a velhice cumpre com o desfecho de um projeto de vida. Para muitos, esse não é um período visto como de possibilidades, mas de conclusões.

De outro modo, Manoela, participante da FINATI, mostra-se bastante otimista quanto ao futuro, pensando, inclusive, em arrumar um emprego. Faz-se necessário, aqui, situar tal fala, a qual parece destoar da maioria, sendo necessário considerar o contexto no qual está inserida, mais presente na área urbana e envolvida em atividades diversas, bem como sua participação na FINATI, que refletem na sua postura. Nesse sentido, é de suma importância considerar as condições sócio-culturais-econômicas na própria vivência do envelhecer. É possível reconstruir os sentidos do envelhecimento e formular experiências mais satisfatórias para os sujeitos.

As mulheres consideram as atividades de lazer muito importantes, o que é observado mais significativamente nas participantes da FINATI, como indica Marisa: "aqui no grupo das idosas a gente faz tudo, é muito bom pra saúde esse grupo, todo mundo diz". A participação na FINATI possibilita, ainda, a ampliação das redes de contatos, o que é sentido como positivo para as mulheres. As demais entrevistadas relatam que fazem caminhadas, não estendendo o sentido de lazer aos vínculos sociais ou a outras atividades. Como aspectos que poderiam melhorar suas condições de vida, Manoela traz a necessidade de ter os filhos mais perto, visto que moram distante; outras três mulheres mencionam desejar melhores condições de saúde ou recursos para mantê-la. Em geral, as idosas da zona rural restringem seus relacionamentos às pessoas de sua comunidade, em especial vizinhos e família. Já os homens, em sua maioria, entendem o lazer como passeios e jogos, no entanto, dois deles identificam no trabalho a experiência de lazer, como aponta Jurandir: "prazer mesmo que eu tenho de trabalho, que é uma galinhazinha, dá de comer ao porco e pronto". Algumas tarefas diárias acabam por se configurar como atividades de lazer, 
que de certa forma suprem a ausência do trabalho, considerado como fonte de satisfação. A manutenção de laços de sociabilidade e a satisfação com os relacionamentos familiares são importantes também nesse contexto, como aspectos comumente relacionados à promoção do bem-estar, acrescido da independência na vida diária e autonomia, conforme apontam Moraes e Souza (2005).

No que diz respeito às ações que o Estado poderia promover para os idosos, dois homens indicam o aumento na aposentadoria ou na forma de fácil liberação de empréstimos; outros dois relatam que poderia aprimorar o atendimento em relação às filas que se acumulam nos espaços onde há oferta de serviços, para que não houvesse tanta espera. Para as mulheres, o governo poderia promover mais ações em saúde, mais investimentos e maior cuidado com os idosos em situação asilar. Entre os 11 entrevistados, nove não possuem conhecimentos sobre o Estatuto do Idoso, não sabem o que significa, tampouco têm ciência de sua finalidade. Ressalta-se aqui a importância do conhecimento acerca dos direitos assegurados à pessoa idosa por parte dessa população, para que deles possam fazer uso.

O recebimento da aposentadoria foi crucial para subsistência dessas famílias, visto que não acumularam posses e sempre se mantiveram com a renda obtida do trabalho na roça, que já não podem mais exercer de modo integral. "No tempo antigo, meu pai, quando morreu, já estava aposentado, mas naqueles anos que não tinha essa aposentadoria, os pobres que tinha um terreninho, vendiam pra se manter, né. E agora com essa aposentadoria, tem seu pedacinho de terra, já não vai vender, porque tem a aposentadoria e quem não tinha terreno pra vender, pra ir comendo, tinha que morrer trabalhando, porque ou trabalhava ou morria de fome, velho sem aguentar mesmo, ia trabalhar" (Juvenal); "Se num fosse a aposentadoria, eu ia viver de quê? Porque eu num trabaio. Tô comendo da aposentadoria." (Oswaldo).

Hoje, verifica-se um crescente desenvolvimento de políticas públicas que visam a atender às necessidades desse grupo geracional em específico, por sua vez, nem sempre o raio de alcance destas atinge áreas populacionais que se mantêm vulneráveis. Tais políticas devem traçar estratégias para promoção social, prevenção em saúde e garantia de direitos humanos, conforme destacam Fernandes e Soares (2012), possibilitando melhorias nas condições de vida.

\section{Considerações finais}

Este artigo foi pautado na análise dos sentidos apresentados pelos idosos no que se refere ao processo de envelhecimento, interligado às vivências experimentadas no trabalho, ou na ausência deste, dentro de uma perspectiva de gênero. Percebeu-se que há similaridades e divergências entre as figuras masculinas e femininas quanto ao processo de saúde/ envelhecimento, embora o foco não estivesse em traçar um comparativo, mas averiguar as particularidades vivenciadas por esses dois grupos.

Os aspectos comumente atrelados ao bem-estar dos idosos estão na esfera ocupacional, relacional e de saúde. O trabalho é visto por ambos os gêneros como importante fator de satisfação, em 
virtude de evitar a ociosidade, bem como para garantir o sustento da família. $\mathrm{O}$ trabalho é exaltado como luta diária, requer força e garante a subsistência. Aqueles que gozam de boas condições físicas mantêm-se em atividade por opção, pois, em termos de renda, recebem aposentadoria, que é o que lhes garante o sustento. As atividades de lavoura que continuam a exercer acrescentam renda extra, mas deixam de se configurar como fonte primordial. As mulheres, responsáveis especialmente pelos cuidados domésticos, continuam a exercê-lo, por sua vez, trazem um envolvimento mais ativo em atividades fora do lar e em situações de convívio social.

Os sentidos atribuídos à velhice direcionam-se para a questão da sua inevitabilidade e valoram positivamente a possibilidade de ter uma vida longa, repleta de experiências, que, por sua vez, aproximam-se de um desfecho caracterizado pela perda de suas funções e da saúde, entendendo que estar velho encerra uma trajetória que não se estenderá muito. Concentram-se no seu dia a dia, desempenhando as tarefas que lhes são atribuídas, sem muitas expectativas futuras.

Em suas falas, atentam para a necessidade de estratégias que resguardem o bem-estar do idoso que vive em zona rural, na forma de ações estatais que aprimorem a oferta de serviços que atendam suas demandas específicas. O local de residência desses idosos não lhes permite acesso fácil aos serviços de saúde, nem às atividades de lazer. Ressalta-se a necessidade de atenção da esfera pública no atendimento em saúde, fornecendo atividades voltadas para esse público, de modo que possam ampliar suas experiências e suas redes sociais, aspectos relacionados à promoção do bem-estar.

\section{Gender, generation and work: ways of life of elderly residents in rural area}

\section{Abstract}

This article presents information obtained from research conducted under the Integrated Center for Research in Social and Health Psychology of Ages Faculty, Paripiranga - BA. The proposal referred to the investigation of the psychological processes of aging linked to the reality of rural labor, under the analytical approach of gender studies. The activities were conducted in the city of Paripiranga - BA, and were divided into three strands: gender, generation and work, being that here the focus is on the analytical approach of gender. Eleven interviews were conducted with elderly, being six men and five women. Of these, eight are residents the field and three living in urban areas, but have some link with the countryside. For information survey used a semi-structured questionnaire containing: 12 personal identification questions, 17 questions about quality of life and aging process; seven questions about work and retirement; seven questions about gender and family roles. Aspects commonly linked to the welfare of the elderly are in the occupational, relational and health spheres. The work is seen as important satisfaction factor, avoids idleness, and ensures the sustenance of the family. Women, especially responsible for home care, continue to exercise it, in turn, bring more active involvement in activities outside the home and in situations of social interaction.

Keywords: Gender. Work. Aging. Health. Rural areas. 


\section{Notas}

1 Pesquisa realizada nas bases de dados SciELO, BVS e Periódicos Capes, em abril de 2012, utilizando os descritores gênero, trabalho e envelhecimento e termos similares.

2 Dados da Prefeitura Municipal de Paripiranga. Disponível em: www.prefeituradeparipiranga. com.br. Acesso: maio de 2012.

\section{Referências}

ABRAMO, L. A situação da mulher latino-americana. O mercado de trabalho no contexto da reestruturação. Proposta, n. 88/89, p. 76-93, mar./ago. 2001. Disponível em: <http://www.fase.org.br/v2/admin/anexos/ acervo/10_lais8889.pdf>. Acesso em: 09 de março de 2013.

BRUSCHINI, C. Gênero e trabalho no Brasil: novas conquistas ou persistência da discriminação? (Brasil, 1985 a 1995). In: Seminário Trabalho e Gênero: mudanças, permanências e desafios. GT População e Gênero Nepo/ Unicamp, São Paulo, 1998. Disponível em: <http://www.abep.nepo.unicamp.br/docs/ outraspub/trabalhogenero/TG_p13a58.pdf>. Acesso em: 20 de out. 2012.

BARDIN, L. Análise de conteúdo. Lisboa: Edições 70, 1979. 229 p.

BULLA, L; KAEFER, C. Trabalho e aposentadoria: as repercussões sociais na vida do idoso aposentado. Revista Virtual Textos e Contextos, ano II, n. 2, p. 1-8, dez. 2003.

DUARTE, C. V.; SANTOS, M. A. "E agora... de quem cuidarei?" O cuidar na percepção de idosas institucionalizadas e não institucionalizadas. Psicologia Ciência e Profissão, n. 1, v. 24, p. 2-13. 2004.

FERNANDES, M. G. M.; GARCIA, L. G. O sentido da velhice para homens e mulheres idosos. Saúde Sociedade São Paulo, v. 19, n. 4, p. 771-783. 2010.
FERNANDES, M. T. O.; SOARES, S. M. O desenvolvimento de políticas públicas de atenção ao idoso no Brasil. Revista Esc. Enfermagem USP, n. 46, v. 6, p. 1494-1502, 2012. Disponível em: <www.ee.usp.br/ reeusp>. Acesso em: maio 2013.

GUSMÃO, N. Velhice e mudança: desafios da contemporaneidade. Revista Coletiva, n. 5, jul./set. 2011. Disponível em: <www.coletiva. org>. Acesso em: out. 2011.

LYRA DA FONSECA, J. L. C. Paternidade adolescente: da investigação à intervenção. In: ARILHA, M.; RIDENTI, S. G. U.; MEDRADO, B. (Orgs.). Homens e masculinidades: outras palavras. São Paulo: ECOS/Ed. 34, 1998. p. 185-214.

MORAES, J.; SOUZA, V. Factors associated with the successful aging of the sociallyactive elderly in the metropolitan region of Porto Alegre. Revista Brasileira de Psiquiatria, n. 4, v. 27, p. 302-308, 2005.

MOTTA, A. B. Gênero e envelhecimento. Revista Coletiva, n. 5, jul./set. 2011. Disponível em: < http://www.coletiva.org/site/index. php?option=com_k2\&view=item\&layout $=\mathrm{i}$ tem\&id $=65 \&$ Itemid $=76 \& i d r e v=8>$. Acesso em: out. 2011.

RIBEIRO, E. E. Tanatologia: vida e finitude. Rio de Janeiro: UERJ, UnATI, 2008. p. 145.

RIDENTI, S. G. U. A desigualdade de gênero nas relações parentais: o exemplo da custódia dos filhos. In: ARILHA, M.; RIDENTI, S. G. U.; MEDRADO, B. (Orgs.). Homens e masculinidades: outras palavras. São Paulo: ECOS/Ed. 34, 1998.

SCOTT, J. Gênero: uma categoria útil de análise histórica. Revista Educação e Realidade, Porto Alegre, v. 16, n. 2, p. 5-22, 1990.

SILVA, L. R. F. Da velhice à terceira idade: 0 percurso histórico das identidades atreladas ao processo de envelhecimento. História, Ciências, Saúde - Manguinhos, Rio de Janeiro, v. 15, n. 1, p. 155-168, jan./mar. 2008. 